\title{
The Use of Fuel Gas as Stripping Medium in Atmospheric Distillation of Crude Oil
}

\author{
C. Plellis-Tsaltakis* and A.I. Lygeros \\ School of Chemical Engineering, National Technical University of Athens, Iroon Polytechneiou 9, Zografou 157 80, Athens - Greece \\ e-mail: cpt@gitech.gr - alygeros@chemeng.ntua.gr \\ * Corresponding author
}

Résumé - L'utilisation de gaz combustible comme moyen d'extraction des fractions légères en distillation atmosphérique du pétrole brut - L'extraction des fractions légères du pétrole vise à enlever les produits nuisibles à certaines propriétés comme le point d'éclair. Cette opération utilise habituellement de la vapeur d'eau. D'autres substances peuvent remplir la même fonction, comme les hydrocarbures légers. Dans cet article, on étudie l'utilisation du gaz combustible de la raffinerie comme moyen d'extraction des fractions légères dans une unité de distillation atmosphérique.

\begin{abstract}
The Use of Fuel Gas as Stripping Medium in Atmospheric Distillation of Crude Oil Stripping of petroleum fractions aims to remove the light ends that spoil some of their properties, such as the flash point. Stripping usually employs steam for that purpose. Except for steam, other substances can perform the same function, among them light hydrocarbons. In this article, we investigate the use of refinery fuel gas as stripping medium for a crude oil atmospheric distillation unit.
\end{abstract}




\section{NOMENCLATURE}

ASTM American Society for Testing and Materials

API American Petroleum Institute

FP Flash Point

$T_{10 \%} \quad$ The ASTM D86 10\% temperature

LPG Liquefied Petroleum Gases

FCC Fluid Catalytic Cracking

ASTM 5-95\% overlap: the difference of the ASTM D86 5\% temperature of a petroleum fraction from the ASTM D86 5\% temperature of the immediately lighter fraction of the same distillation column.

IRR Internal Rate of Return

BOD Biological Oxygen Demand

TBP True Boiling Point

wt Weight

\section{INTRODUCTION}

Distillation is widely used to separate hydrocarbon mixtures, like crude, into their products. Due to the finite number of stages, their efficiency and the finite reflux rate, the separation is not perfect. This imperfection manifests itself in the form of light and heavy "tails" of the distillation curves of the products (Fig. 1). The heavy tail of the top product can be smoothed increasing the reflux ratio. This move will at the same time, drive more of the light components in the heavy product, worsening this way its light tail. The light tail can be removed from the heavy product with a stripper. Usually it is a short distillation column, which the untreated product enters from the top, while steam is routed beneath the bottom stage. The steam dilutes the hydrocarbons in the vapor phase of each stripper stage, reducing thus their partial pressure. The reduction of the partial pressure causes more hydrocarbons to evaporate. The light tails evaporate selectively, because of their lower boiling points.

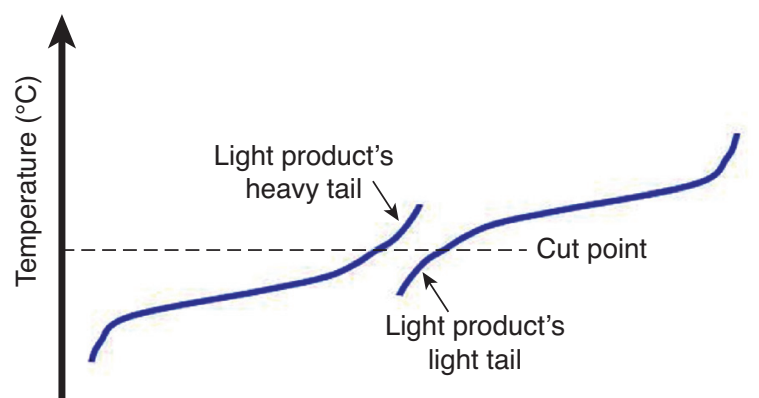

$\%$ vol on crude

Figure 1

Typical TBP curves show heavy and light tails of the distillation products.
The stripping can be also performed with alternative media other than steam. These stripping media can be light hydrocarbons, incondensable at the operating conditions. The earliest reference to this by Nelson [1]. Ji and Bagajewicz [2] name this behaviour "carrier effect" and state that they have developed technology to implement it in crude distillation, without providing any details on the proposed modifications. Mel'nikov et al. [3], discussed the possibility of using different stripping media, other than steam, including hydrotreater recycle gas. The authors proposed a complex flowsheet consisting of a two stage fractionation of the crude, a recycle loop for the stripping medium and two absorber columns for the reclamation of the LPG and naphtha range compounds that the stripping medium will carry over in the gaseous phase. However, the article assumes identical product quality and yields regardless of the stripping media. This assumption does not agree either with Ji and Bagajewicz, or with the results of the work described in the current article, which tries to investigate the feasibility of a proposed flow sheet for the increase of crude distillation yield by use of the "carrier effect".

\section{METHODS}

The operation of an existing crude distillation unit was simulated, using Aspen Plus. The column (Fig. 2) has 4 side products, light and heavy kerosene and light and heavy gasoil. The distillation column has 44 actual trays which make up 34 theoretical stages. The section between overhead and light kerosene has 5 stages, between light and heavy kerosene 12, between heavy kerosene and light gasoil 9, between light and heavy gasoil 6, between heavy gasoil and flash zone 3 and 4 stages at the stripping section. It has 2 pumparounds, one between light and heavy kerosene trap out trays (15 Mkcal/h) and one between light and heavy gasoil $(9 \mathrm{Mkcal} / \mathrm{h})$. The top product is unstabilized naphtha, (naphtha and LPG). It operates at a feed rate of $575 \mathrm{MT} / \mathrm{h}$. It uses $9 \mathrm{MT} / \mathrm{h}$ of superheated stripping steam. Its overhead system has two drums, one operating as surge drum for the reflux and one as surge drum for the top product. The first drum operates at temperatures safely above the dew point of water, in order to prevent corrosion of the column's top. The column operates at 3.7 bar(a) at the top tray.

The thermodynamic package used for the modeling was the Soave - Redlich - Kwong equation of state, which is very accurate for hydrocarbon mixtures at the pressure and temperature conditions of the atmospheric distillation [4-6]. It can also handle mixtures containing $\mathrm{H}_{2}$, as it uses a correlation specifically derived for hydrogen, to calculate the Soave parameter, $\left(\alpha_{\mathrm{H}_{2}}\right)$, for this component [7]. The equation of state is also suitable for mixtures containing $\mathrm{CO}_{2}, \mathrm{H}_{2} \mathrm{~S}, \mathrm{~N}_{2}, \mathrm{CO}$ by use of suitable binary interaction parameters $[8,9]$. 


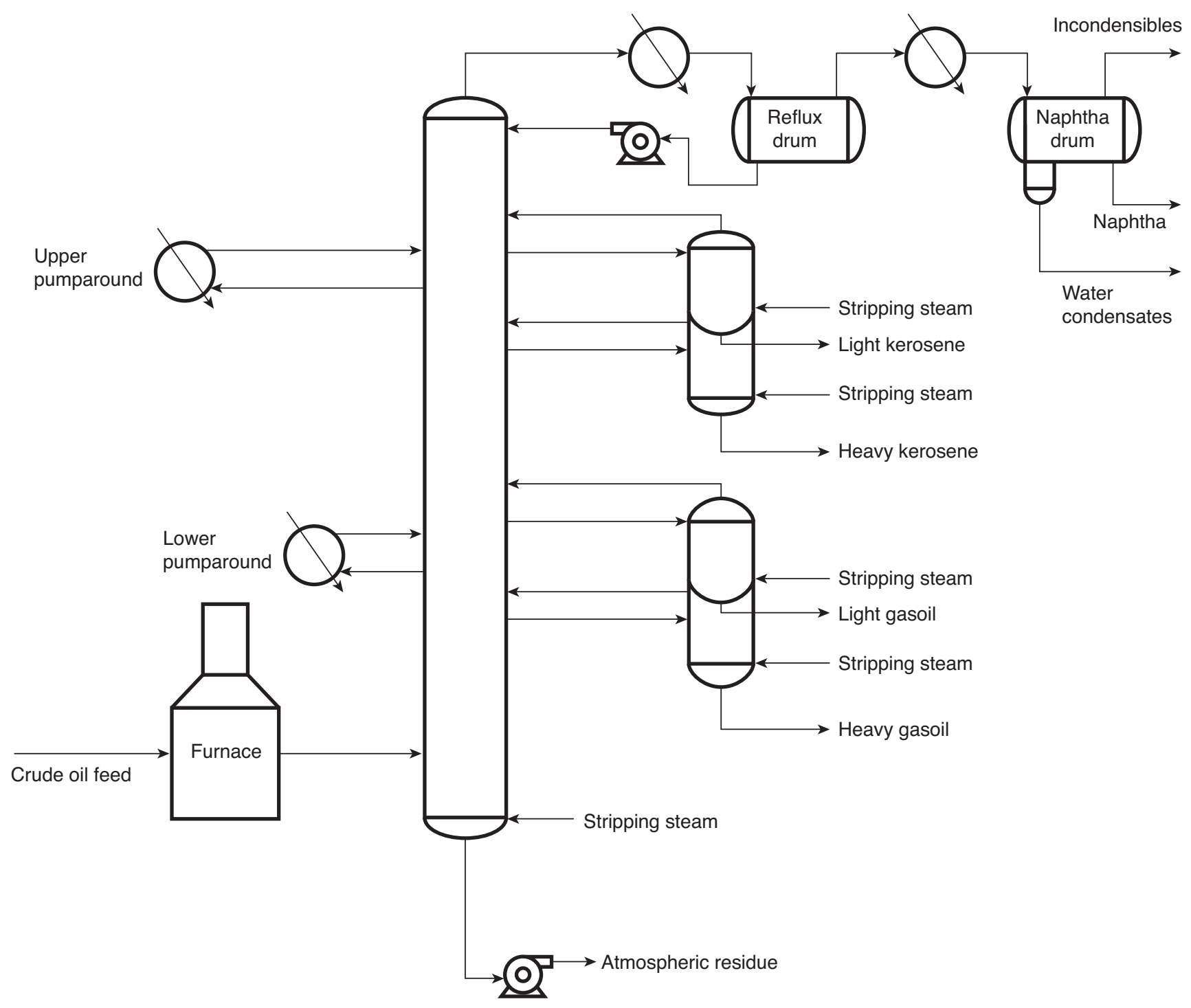

Figure 2

Atmospheric distillation flowsheet.

The model was used to predict the operation of the unit with alternative stripping media. The alternative medium selected is the refinery fuel gas. It is a mixture of incondensable light hydrocarbon gases. Its main components are ethane and ethylene. Fuel gas in modern refineries is almost always amine treated, for the removal of $\mathrm{H}_{2} \mathrm{~S}$. The stripping medium in the proposed process is being recirculated, with a suitable compressor. For this reason, the net fuel gas consumption, (due to stripping medium solubility in the products), is rather small, calculated as $2 \mathrm{~kg} / \mathrm{MT}$ of feed. For the feed rates of usual commercial units, this corresponds to $100-200 \mathrm{~kg}$ fuel gas $/ h$, which is a very small quantity and should not have any measurable impact on the amine treating units of any refinery.
Components heavier than ethane are removed as much as possible, so as to reduce the loss of condensable components that could otherwise be marketed. Moreover, as the industry continuously moves towards deeper hydrotreated fuels, the $\mathrm{H}_{2}$ excess in the fuel gas continuously diminishes. Of course, each refinery has a unique composition of fuel gas, which is not always the same, but depends on the operating conditions of the various units. For this reason before implementing modifications of the sort described in the present work, detailed studies should be carried out, taking into consideration the uniqueness of each case. On the other hand, this paper aims to demonstrate the feasibility of the general process philosophy of substituting the stripping steam with 
fuel gas and to define the demanded new equipment and the modifications to the existing one. For the needs of this paper, fuel gas was modeled as ethane.

In order for the distillation unit to operate with the alternative stripping medium, many changes of the process flow diagram were employed, which will be described in the next paragraphs. The distillate yields and the utility consumptions are calculated by the simulation, for both processes. The cost of modification of the process is estimated and the economic feasibility of the proposed modification is determined, in the last paragraph of the discussion of the results.

The proposed process could be used for existing units revamping as well as for new, grassroots designs. In this paper we choose to investigate the feasibility of revamping an existing unit, in order to be able to compare the performance of the conventional process to that of the proposed. In order to ensure the comparability of the two processes, the following constraints are set:

- both units operate with the same crude, at the same feedrate;

- the final boiling point of each distillate of the modified process is the same with that of the corresponding distillate of the conventional;

- in the cases of light and heavy kerosene, the Flash Point of each distillate of the modified process is the same with that of the corresponding distillate of the conventional. The Flash Points can be estimated from the $10 \%$ boiling point temperature of the ASTM D-86 distillation, using the API- 2B7.1 procedure $(E q .1,2)$.

$$
\begin{aligned}
& \text { Closed cup: } \mathrm{FP}=0.69 \times T_{10 \%}-118.2 \\
& \text { Open cup: } \mathrm{FP}=0.68 \times T_{10 \%}-109.6
\end{aligned}
$$

where FP is the Flash Point $\left({ }^{\circ} \mathrm{F}\right)$, and $T_{10 \%}$ is the ASTM D86 10\% temperature $\left({ }^{\circ} \mathrm{F}\right)$.

Because the modified process is more efficient than the conventional, its distillate yields are greater that those of the conventional, when the above constraints are enforced.

\section{MODIFICATION OF THE CRUDE DISTILLATION UNIT FLOW DIAGRAM}

\subsection{Alternative Stripping Medium Selection}

As stated above, ethane was chosen as an alternative stripping medium, as a model for refinery fuel gas. Alternatively, methane or propane could be used. Methane was ruled out, because it is neither present in significant quantities in the crude oil, nor is it produced by the usual refinery processes. Propane is condensable at the conditions of the atmospheric distillation overhead system. In the same time it has a significantly higher molecular weight than ethane, which would increase the brake horse power of the stripping medium recycle compressor.

\subsection{Once - Through Stripping Medium Operation}

The first simulations involved no changes of the process flow diagram, just the replacement of the stripping steam with ethane. The predicted operation let us find out two major consequences, the loss of unstabilized naphtha yield and the reduction of the distillate Flash Points.

Specifically, major amounts of the LPG (82\% wt) and of naphtha $(40 \% \mathrm{wt})$ remain incondensable at the operating conditions of the overhead drum. This phenomenon is widely known at the FCC units, where the fractionation of the reactor products takes place in the presence of major amounts of fuel gas. In order to reclaim the light products from the fuel gas, a wet gas compressor is utilized to increase the pressure and the mixture is separated in a gas plant consisting of four columns.

Moreover, small amounts of ethane are soluble in the side products of the column, decreasing their Flash Point.

In order to optimize the operation of the distillation unit, with the alternative stripping medium, a series of modifications of the process flow diagram was introduced, which will be described in the next paragraph. The modified flow diagram is presented in Figure 3.

\subsection{Introduction of Recycle Compressor}

The next step was to introduce a recycle compressor for the stripping medium. The compressor will be of centrifugal type and will have a cooler and a knock - out drum at the suction. The compressor will recycle the stripping medium to the process. Further to saving vast amounts of recycle gas, this significantly lowers the light product losses to the incondensables, because the recycled stripping medium becomes saturated in these compounds. Again, the losses remain high, (15\% wt of LPG and $7 \%$ wt of naphtha). The stripping gas recycle circuit will have a bleed stream, to remove part of the gas, so as to be able to control the molecular weight of the recycle gas. The circuit will be completed with a stripping gas addition valve (fuel gas make-up), which will be utilized to replenish the gas vented by the bleed and the gas lost due to its solubility in the products and atmospheric residue. Controlling the molecular weight of the stripping gas has a significant effect on the power consumption of the recycle gas compressor.

The modifications described in the next paragraph completely resolved the loss of light products and the decrease of the Flash Point.

\subsection{Other Process Flow Diagram Modifications}

Instead of employing a gas plant to reclaim the light products, we decided to include a preflasher in the unit. The preflasher 


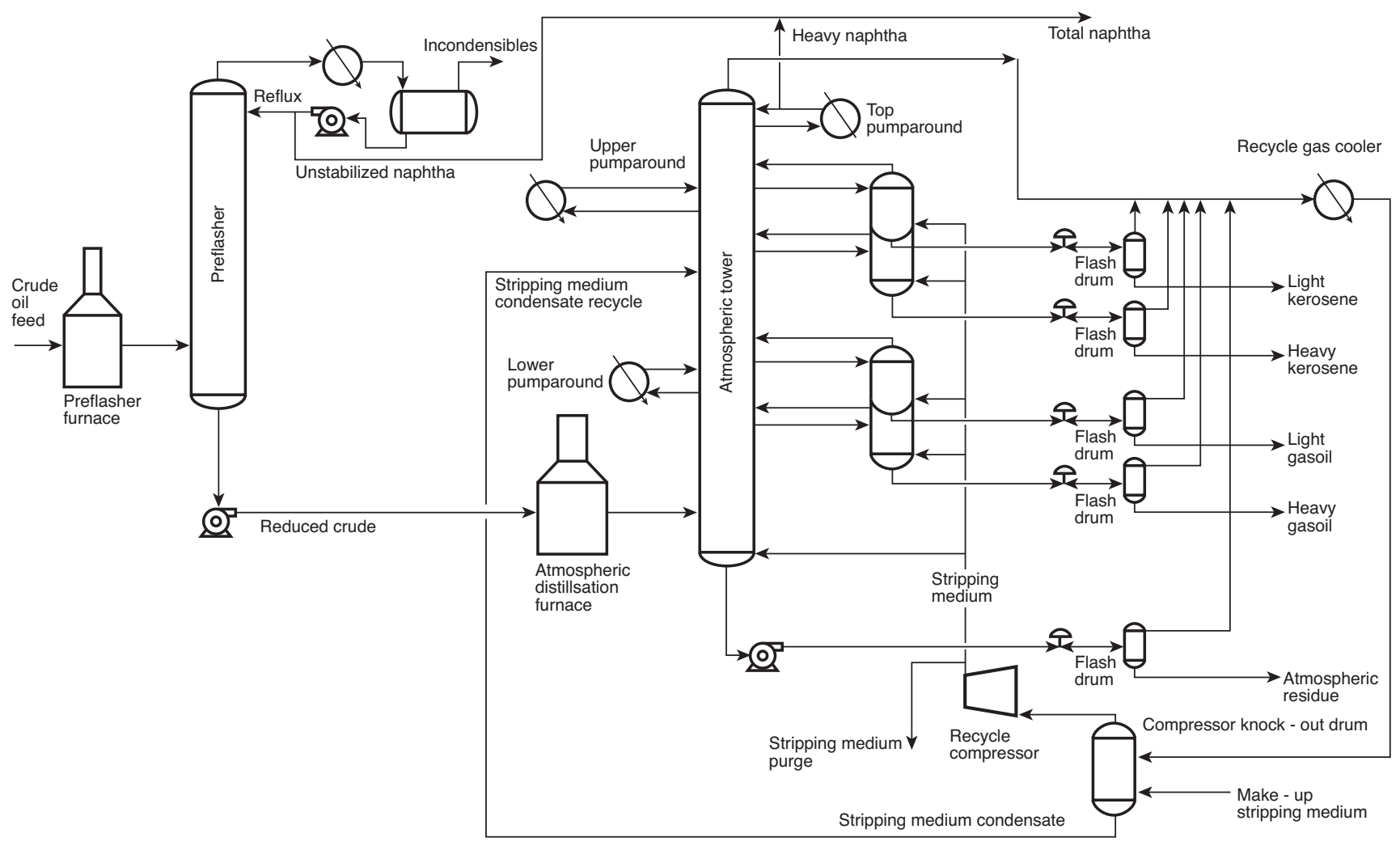

Figure 3

Modified atmospheric distillation flowsheet.

column will operate without stripping medium and will be able to separate all the unstabilized naphtha from the crude. This way, we prevent the formation of the mixture of the stripping medium with the light products instead of trying to separate it. The preflasher column will have its own furnace and overhead system.

We decided to replace the overhead system of the column with a pumparound, in order to avoid vapor binding $[10,11]$ of any shell and tube heat exchangers by the incondensable stripping gas. The old overhead system will be used as is for the preflasher column. Because all unstabilized naphtha is removed at the preflasher, the atmospheric distillation column operates at total reflux, with only vapor top product. This mode of operation has also a negative consequence. Because no separation is perfect, small amounts of heavy naphtha grade compounds are entrained in the bottom product of the preflasher and enter the atmospheric distillation column. Total reflux dictates that these compounds can exit the column only as light ends of the first side stream (light kerosene). The side effect is lowering of the Flash Point of this product. In order to give to the column the ability to control the Flash Point of light kerosene, we add a small slip stream of heavy naphtha (a small part of the top pumparound of the column), so as to give to the entrained heavy naphtha a way out of the column other than the first side stream. The small amount of heavy naphtha can be blended directly to the unstabilized naphtha of the preflasher.

In order to remove the small amounts of the ethane that is soluble in the side products, we added to the model flash drums, one for each of the products, which will remove the dissolved ethane, by flashing the products to the lowest achievable pressure, i.e. $0.1 \mathrm{bar}(\mathrm{g})$. The gas effluent of these drums is routed to the recycle gas compressor suction. Prior to the recompression, the recycle gas is cooled to $40^{\circ} \mathrm{C}$ and the condensed hydrocarbons are removed at the compressor suction knock out drum. These condensates could be recycled back to the feed of the column. This would significantly increase the duty of the fired heater, with their latent heat of vaporization. Instead, we decided to recycle this stream to the column, at the tray which has the liquid that resembles more the composition of the condensate stream. This way, instead of increasing the fired heater duty, we decrease the required cooling duty of the column. 


\section{RESULTS}

\subsection{Distillate Yields}

The modified atmospheric distillation process achieves $3.1 \%$ wt better yields on the crude, than the conventional. The yields of the conventional and modified process are summarized in Table 1. As previously stated, constraints for the increase of the yields were the quality related properties of the products (final boiling points). For the first and second side streams (light and heavy kerosene), also the Flash Points were considered as constraints.

TABLE 1

\begin{tabular}{c|c|c|c}
\multicolumn{4}{c}{ Yields } \\
\hline Products & $\begin{array}{c}\text { Modified } \\
\text { unit }\end{array}$ & $\begin{array}{c}\text { Conventional } \\
\text { unit }\end{array}$ & Difference \\
\hline Unstabilized naphtha & $19.2 \%$ & $17.6 \%$ & $1.6 \%$ \\
\hline Light kerosene & $4.5 \%$ & $6.7 \%$ & $-2.2 \%$ \\
\hline Heavy kerosene & $9.3 \%$ & $8.9 \%$ & $0.4 \%$ \\
\hline Light gasoil & $10.6 \%$ & $10.5 \%$ & $0.1 \%$ \\
\hline Heavy gasoil & $11.8 \%$ & $8.6 \%$ & $3.2 \%$ \\
\hline Atmospheric residue & $44.6 \%$ & $47.7 \%$ & $-3.1 \%$ \\
\hline Total distillate yield & $55.4 \%$ & $52.3 \%$ & $3.1 \%$ \\
\hline
\end{tabular}

Table 2 presents the achieved separation between the adjacent products of the unit, as compared to those of the conventional process. The separation is expressed as ASTM 5-95\% overlap. From the data of the table, we can conclude that the separation the modified process achieves is similar to the conventional one and even better than the conventional in the case of the separation between heavy gasoil and atmospheric residue.

\section{TABLE 2}

ASTM 5\%-95\% overlap

\begin{tabular}{c|c|c|c}
\hline & \multicolumn{3}{|c}{ ASTM 5\%-95\% overlap $\left({ }^{\circ} \mathrm{C}\right)$} \\
\hline Products & $\begin{array}{c}\text { Modified } \\
\text { unit }\end{array}$ & $\begin{array}{c}\text { Conventional } \\
\text { unit }\end{array}$ & Difference \\
\hline Naphtha - light kerosene & 11.4 & 4.4 & -7.1 \\
\hline Light kerosene - heavy kerosene & 8.5 & 17.5 & 9.0 \\
\hline Heavy kerosene - light gasoil & 12.8 & 15.2 & 2.4 \\
\hline Light gasoil - heavy gasoil & 34.4 & 27.5 & -6.9 \\
\hline Heavy gasoil - atmospheric residue & 61.3 & 98.9 & 37.7 \\
\hline
\end{tabular}

The enhancement of the yield on crude can be attributed partially to the introduction of the preflasher and partially to the alternative stripping medium. A direct calculation of the benefits of each of these two modifications is not possible, because the operation of the atmospheric distillation with ethane as stripping medium without the preflasher is not possible, as it leads to the loss of great amounts of unstabilized naphtha to the incondensible gases, Section 2.3. Nevertheless, the increase of unstabilized naphtha yield $(1.6 \%)$ is solely due to the preflasher.

At the same time, simulation of the same unit, with preflasher, but operating with steam as stripping medium and at the same operating conditions as the proposed one, has a decreased yield in the side streams and a total yield of only $50.6 \%$. This decrease can be attributed to the removal of all the naphtha and lighter compounds at the preflasher column. These light materials would otherwise be present in the flash zone of the main distillation column as vapor, which would have a stripping effect on the gasoil range distillates and increase their recovery from the atmospheric residue [1].

Thus, Table 3 presents the difference of the yields of the two processes.

TABLE 3

$\%$ wt yields of conventionally and fuel gas stripped process

\begin{tabular}{c|c}
\hline Process & Distillate yield (\% wt) \\
\hline Preflashed, stripped with ethane & $55.4 \%$ \\
\hline Preflashed, stripped with steam & $50.6 \%$ \\
\hline Difference & $4.8 \%$ \\
\hline
\end{tabular}

As discussed in the previous paragraph, both processes have increased unstabilized naphtha yield, in comparison to the conventional, non - preflashed, steam stripped process. This implies that $1.6 \%$ wt of the $4.8 \%$ wt yield increase can be attributed solely to the preflasher. Thus, the yield increase (in comparison to the conventional process), attributable to the different stripping medium is:

$$
4.8 \%-1.6 \%=3.2 \%
$$

In other words, the enhancement of the yield on crude can be attributed by $33 \%$ to the introduction of the preflasher and $66 \%$ to the alternative stripping medium.The light components of the fuel gas outperform stripping steam as a stripping medium. Although the explanation of this effect of the composition of the stripping medium is out of the scope of this paper, we can state that it lies at the balance of intermolecular forces at the vapor and liquid phases of each tray of the column. The non - polar hydrocarbon molecules of the alternative stripping medium reduce the attraction forces that aid the condensation while in the same time occupy greater space in the liquid phase, reducing in this way the mean free path in 
it [12-14]. The effect of this is increase of the intermolecular collisions, or in other terms increase of the repulsion forces, which increase the vapor pressure of the liquid, aiding thus its vaporization.

\subsection{Economics}

The enhanced yields that the proposed modification of the atmospheric distillation process achieves, has to be compared to the cost increase it incurs. The extra cost is partially due to the value of the additional equipment needed and partially due to its extra operating costs (electric power for the recycle compressor, extra fuel for the preflasher's fired heater). The total cost of modification (equipment + erection + commissioning + interconnection downtime cost) is estimated as 32.6 million USD (Tab. 4).

The annual cash flow increase (unit yield increase + saved cost of stripping steam - electric power cost of recycle compressor - extra fuel cost for preflasher furnace - depreciation - 25\% taxes) is calculated as 26.2 million USD. From these numbers we calculate a payout period of 15 months and an Internal Rate of Return, (IRR) of $81 \%$.

TABLE 4

Investment cost

\begin{tabular}{l|c|c|r}
\hline Equipment & Size & Number & Cost \\
\hline Preflasher column & $236 \mathrm{~m}^{3}$ & 1 & $\$ 1130000$ \\
\hline Preflasher fired heater & $30 \mathrm{Mkcal}$ & 1 & $\$ 2500000$ \\
\hline $\begin{array}{l}\text { Atmospheric tower top pumparound } \\
\text { exchanger }\end{array}$ & $10 \mathrm{Mkcal}$ & 1 & $\$ 600000$ \\
\hline Compressor knockout drum & $28 \mathrm{~m}^{3}$ & 1 & $\$ 226000$ \\
\hline Product flash drums & $9 \mathrm{~m}^{3}$ & 5 & $\$ 70500$ \\
\hline Compressor suction cooler & $4 \mathrm{Mkcal}$ & 1 & $\$ 300000$ \\
\hline Preflasher bottom pump & & 2 & $\$ 200000$ \\
\hline Stripping medium recycle compressor & $4 \mathrm{MW}$ & 1 & $\$ 4500000$ \\
\hline $\begin{array}{l}\text { Atmospheric tower top pumparound } \\
\text { pump }\end{array}$ & & 2 & $\$ 120000$ \\
\hline Erection cost & & & $\$ 9646500$ \\
\hline 20 day unit turnaround cost & & & $\$ 13300000$ \\
\hline Total investment cost & & & $\$ 32593000$ \\
\hline
\end{tabular}

In order to estimate the risk of investing in such a modification, a sensitivity analysis was carried out. The results of the analysis are summarized in Table 5. The percentages presented in the table are the cost parameter increases that would render the investment unattractive (IRR $=12 \%$ ). In order to be on the safe side for the purposes of the risk calculation, we supposed that the modification does not achieve the calculated yield increase of $3.1 \%$ wt, but only $2.4 \% \mathrm{wt}$ (we assume $20 \%$ error in the calculations of the operation of the unit).

TABLE 5

Sensitivity analysis

\begin{tabular}{c|c}
\hline Cost parameter & Increase to render the IRR =12\% \\
\hline Power cost $(\$ / M W h)$ & $1187 \%$ \\
\hline Fuel oil cost (\$/MT) & $29 \%$ \\
\hline Margin (diesel - fuel oil) (\$/MT) & $-43 \%$ \\
\hline Installed equipment cost & $343 \%$ \\
\hline
\end{tabular}

From these data, it is apparent that the risk is very small. Even if the fuel oil cost increases by $29 \%$, the same will apply to the values of the distillates, which will keep the investment profitable. Shrinkage of the margin of the diesel versus fuel oil by $40 \%$ is not possible, because the markets of the gasoil continuously increases while that of fuel oil diminishes.

\section{CONCLUSIONS}

It is possible to design, construct and operate crude oil atmospheric distillation columns that use fuel gas instead of stripping steam. The proposed mode of operation results in increased distillate yields, which considerably improve the economics of the unit. The proposed modification is based on the "stripping effect" of the light hydrocarbons, i.e. their ability to create incondensable mixtures with heavier components. This effect is widely known at cracking units. Thermal or catalytic cracking creates mixtures of propane and heavier compounds, with big amounts of ethane and ethylene. In order to reclaim their condensable components, these mixtures have to be significantly compressed and processed either with recontacting with a liquid hydrocarbon stream, or in a gas concentration unit.

The heavy naphtha side product gives more operating flexibility with respect to achieving the specifications of naphtha and light kerosene.

The proposed process design can be applied both to revamping of existing units and to new units.

Using light hydrocarbons as stripping media instead of steam reduces considerably the water present in the distillation system. This can eliminate or at least alleviate many operational and maintenance problems, such as:

- all crudes contain sulfur compounds. They also contain $\mathrm{CaCl}_{2}$ and $\mathrm{MgCl}_{2}$. These compounds can be partially broken down at the operating conditions of the unit, and in the presence of water, produce acids which corrode the top of the distillation column, at sub dew point locations. Less water in the column reduces the severity of such problems; 
- the condensation of the stripping steam at the overhead condenser produces significant amounts of BOD laden water that the waste water treatment facility of a plant has to treat;

- the enthalpy of condensation of steam is about five times that of hydrocarbons. Substituting the steam with hydrocarbons could remove a considerable cooling load from the overhead system, reducing thus the operating pressure at hot seasons and allowing for a small feed increase;

- the use of stripping steam is a potential danger for the integrity of fractionating equipment, in case it introduces liquid water in the column;

- plants could significantly reduce their raw water consumption. The alternative stripping media are substances abundant in a crude oil refinery.

Utilization of alternative stripping medium for the atmospheric distillation of crude oil is a new, innovative approach to the most common refinery process. The yield increase it can achieve, $3.1 \%$ wt, might seem small, but taking into consideration that such units have feedrates in the order of $600 \mathrm{MT} / \mathrm{h}$, it corresponds to almost 150000 MT/year of additional distillates recovery from the atmospheric residue. The conventional atmospheric distillation process exists for more than a century. In this period it has become as efficient as it can get, with the conventional approach. Any significant increase of its efficiency has to be gained with modifications as radical as the replacement of stripping steam with hydrocarbons.

\section{REFERENCES}

1 Nelson W.L. (1958) Petroleum Refinery Engineering, 4th ed., New York.

2 Ji S., Bagajewicz M. (2002) New Insights on the Carrier Effect in Crude Distillation, NPRA Annual Meeting 2002, San Antonio, TX, March 17-19.

3 Mel'nikov V.S. et al. (1984) Hydrocarbon gas as stripping agent in atmospheric towers of atmospheric-vacuum tubestill units, Chem. Technol. Fuels Oils 20, 5.

4 Kaes G.L. (2000) Refinery Process Modeling, Athens Printing Company, Athens, Georgia.

5 Luyben W. (2006) Distillation Design and Control Using Aspen Simulation, Wiley, Hoboken.

6 Finlayson B.A. (2006) Introduction to Chemical Engineering Computing, Willey, Hoboken.

7 Soave G. (1972) Equilibrium Constants from a Modified Redlich - Kwong Equation of State, Chem. Eng. Sci.27, 6.

8 Graboski M.S., Daubert T.E. (1978) A Modified Soave Equation of State for Phase Equilibrium Calculations I. Hydrocarbon Systems, Ind. Eng. Chem. Process Des. Dev. 17.

9 Graboski M.S., Daubert T.E. (1978) A Modified Soave Equation of State for Phase Equilibrium Calculations II. Systems Containing $\mathrm{CO}_{2}, \mathrm{H}_{2} \mathrm{~S}, \mathrm{~N}_{2}$ and $\mathrm{CO}$, Ind Eng. Chem. Process Des. Dev. 17.

10 Lieberman N.P. (2003) Working Guide to Process Equipment, 2nd ed., McGraw Hill, New York.

11 Lieberman N.P. (1991) Troubleshooting Process Operations, 3rd ed., Pennwell, Tulsa.

12 Alberty R.A. (1991) Physical Chemistry, 6th ed., Wiley, New Delhi.

13 Castellan G.W. (1990) Physical Chemistry, 3rd ed., Narosa Publishing House, New Delhi.

14 Loeb L. (1985) The Kinetic Theory of Gases, 3rd ed., Radha Publishing House, Calcutta.

Final manuscript received in February 2011 Published online in September 2011 